\title{
Angelman Syndrome
}

National Cancer Institute

\section{Source}

National Cancer Institute. Angelman Syndrome. NCI Thesaurus. Code C75462.

A genetic syndrome characterized by mental retardation, speech impairment,

microcephaly, ataxia, and seizures. The majority of cases result from deletions on the

long arm of chromosome 15. A minority of cases result from mutations in the UBE3A gene. 